\title{
Measures of Multimorbidity and Morbidity Burden for Use in Primary Care and Commu- nity Settings: A Systematic Review and Guide
}

\author{
Alyson L. Huntley, BSc, $P b D^{1}$ \\ Racbel Jobuson, MRCGP \\ Sarab Purdy, MPH, MD, FRCGP \\ Jose M. Valderas, $M D, P b D, M P H^{2}$ \\ Chris Salisbury, MSc, MD, FRCGP \\ 'Academic Unit of Primary Health Care, \\ School of Social and Community Medicine, \\ Bristol University, Bristol, England \\ ${ }^{2}$ Health Services and Policy Research \\ Group, Department of Primary Health \\ Care, Oxford, England
}

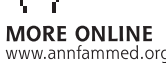

Conflicts of interest: authors report none.

\section{CORRESPONDING AUTHOR}

Chris Salisbury, MSc, MD, FRCGP Academic Unit of Primary Health Care School of Social and Community Medicine Canynge Hall, Bristol University Bristol, BS8 2PS, England c.salisbury@bristol.ac.uk

\begin{abstract}
PURPOSE Many patients consulting in primary care have multiple conditions (multimorbidity). Aims of this review were to identify measures of multimorbidity and morbidity burden suitable for use in research in primary care and community populations, and to investigate their validity in relation to anticipated associations with patient characteristics, process measures, and health outcomes.
\end{abstract}

METHODS Studies were identified using searches in MEDLINE and EMBASE from inception to December 2009 and bibliographies.

RESULTS Included were 194 articles describing 17 different measures. Commonly used measures included disease counts $(n=98)$, Chronic Disease Score (CDS)/ RxRisk $(n=17)$, Adjusted Clinical Groups (ACG) System $(n=25)$, the Charlson index $(n=38)$, the Cumulative Index Illness Rating Scale (CIRS; $n=10)$ and the Duke Severity of Illness Checklist (DUSOI; $n=6$ ). Studies that compared measures suggest their predictive validity for the same outcome differs only slightly. Evidence is strongest for the ACG System, Charlson index, or disease counts in relation to care utilization; for the ACG System in relation to costs; for Charlson index in relation to mortality; and for disease counts or Charlson index in relation to quality of life. Simple counts of diseases or medications perform almost as well as complex measures in predicting most outcomes. Combining measures can improve validity.

CONCLUSIONS The measures most commonly used in primary care and community settings are disease counts, Charlson index, ACG System, CIRS, CDS, and DUSOI. Different measures are most appropriate according to the outcome of interest. Choice of measure will also depend on the type of data available. More research is needed to directly compare performance of different measures.

Ann Fam Med 2012;10:134-141. doi:10.1370/afm.1363.

\section{INTRODUCTION}

7 here is increasing interest in the concept of multimorbidity, which is the co-occurrence of multiple diseases or medical conditions within 1 person. ${ }^{1}$ Multimorbidity is particularly important in generalist settings, such as primary care, where family practitioners act as the first point of contact for people with a wide range of conditions and frequently manage patients with multiple coexisting conditions. Most patients consulting in family practice have multimorbidity, and the number of coexisting conditions increases with age. ${ }^{2-4}$ The presence of multimorbidity is associated with increased health service utilization and poorer health outcomes..$^{5-8}$

To assess the impact of multimorbidity, it is necessary to measure it. Measures of multimorbidity broadly fall into 2 types: simple counts of diseases in each individual (based on patient self-report or clinician assessment), and indices to assess morbidity burden that differentially weight a range of conditions or diseases, using weights based on mortality, severity, or likely resource utilization. ${ }^{1}$ 
Many measures of multimorbidity and comorbidity were originally developed and validated among selected patients in hospital settings. The reliability and validity of some of these measures in a range of settings have previously been reviewed by de Groot et $\mathrm{al}_{1}{ }^{9}$ but the findings may not be relevant to primary care, as the validity of a measure depends on the patient group and context in which it is assessed. Furthermore, their review was based on articles published before September 2000 and needs updating.

The current review focuses on the use of measures of multimorbidity in family practice, generalist ambulatory care settings, and community dwelling populations. In the context of this review, we have defined primary care and community settings broadly to ensure relevance to the different health systems providing primary care in different countries.

The aims of this review were (1) to identify and describe measures of multimorbidity that are most suitable for use in research in primary care and community populations, taking into account the data and resources they require; and (2) to investigate the validity of these measures in terms of whether they have demonstrated anticipated associations with patient characteristics, process measures, and health outcomes.

\section{METHODS}

\section{Inclusion Criteria}

We included studies with empirical data that enabled us to assess the validity and/or reliability of measures of multimorbidity when used in generalist primary care or population settings.

Assessment of validity depends on determining whether a measure is able to demonstrate associations that support an underlying theory about the relationship between the construct being measured and other variables. ${ }^{10}$ Because the nature of these anticipated relationships will vary in different settings, rather than addressing the validation of a measure, it is appropriate to assess the validity of a measure in a specific group of people and a specific context. ${ }^{11}$

For this review, we included studies that provided data about associations between measures of multimorbidity and (1) patient sociodemographic characteristics, such as age, sex, and deprivation; (2) worse health outcomes; and (3) process measures, such as utilization of health care, costs, and quality of care. It was anticipated that a valid measure of multimorbidity would demonstrate associations with these variables. We also sought to identify articles comparing one measure of multimorbidity against another. Finally, we sought to identify articles that demonstrated the test-retest, intrarater or interrater reliability of these measures when used in a primary care or community context.

We included quantitative studies of any design that were predominantly based on adults. Participants had to be identified either from a generalist primary care setting or a population sample. We did not restrict searches by country or language, although we did require an English abstract.

\section{Exclusion Criteria}

We excluded studies in which participants were identified through their contact with specialist services or hospital admission. We also excluded studies of measures in which the presence of an index disease was integral to the measure (for example, measures specific to diabetes); studies of comorbidity (an additional disease in patients with a specified index disease); studies in which the multimorbidity measure was only used to show associations with variables related to secondary care (for example, in-patient mortality); and studies that described the prevalence of multimorbidity without studying associations with other variables.

\section{Searches}

We conducted a systematic review through searches in MEDLINE and EMBASE from inception to December 2009. Searches were undertaken in 3 stages, which were then combined. MeSH headings and free text were used to identify terms relating to (1) multimorbidity or comorbidity; $(2)$ measures or indexes and terms for measures that we had already identified; and (3) ambulatory, outpatient, primary, or community care or general/community population.

The searches were developed iteratively to identify the combinations of terms that achieved an acceptable level of sensitivity and specificity. We repeatedly checked articles identified through different strategies against relevant articles already identified and articles identified through existing bibliographies. ${ }^{12-14} \mathrm{We}$ also selected other articles from our personal files, contacted other researchers, and checked reference lists from relevant articles. The final search strategy is shown in the Supplemental Appendix, available at http:// annfammed.org/content/10/2/134/suppl/DC1.

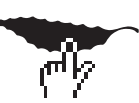

\section{Data Management and Extraction}

One author (A.H.) conducted a preliminary screen of titles and abstracts to exclude articles that were clearly irrelevant. Abstracts from the remaining studies were screened independently by 2 authors to identify potentially relevant articles that were then reviewed independently in full text. Disagreements were resolved between the 2 authors, with discussion with a third author as necessary. 


\begin{tabular}{|c|c|c|c|}
\hline Measure & $\begin{array}{l}\text { Original Derivation/ } \\
\text { Validation Populations }\end{array}$ & Information Needed & Original Purpose of Score \\
\hline Disease count & $\begin{array}{l}\text { Not applicable (varies for different } \\
\text { studies) }\end{array}$ & $\begin{array}{l}\text { Clinician-rated disease counts derived from } \\
\text { medical records or clinician diagnosis } \\
\text { Self-reported disease counts based on ques- } \\
\text { tionnaires or interviews }\end{array}$ & $\begin{array}{l}\text { Not applicable (varies for differ- } \\
\text { ent studies) }\end{array}$ \\
\hline $\begin{array}{l}\text { Chronic Disease } \\
\text { Score (CDS)/ } \\
\text { RxRisk } \\
\text { Model }^{15-17}\end{array}$ & $\begin{array}{l}\text { Original CDS }{ }^{15} \text { : adult HMO enrollees } \\
\text { from a single US HMO } \\
\text { Revised CDS }{ }^{16} \text { derived and validated in } \\
254,694 \text { adult members of a US HMO. } \\
\text { RxRisk }{ }^{17} \text { derived and validated in large } \\
\text { samples of US HMO enrollees }\end{array}$ & $\begin{array}{l}\text { Automated pharmacy data during a 1-year } \\
\text { period }\end{array}$ & $\begin{array}{l}\text { To develop a stable measure of } \\
\text { chronic disease status using } \\
\text { routine pharmacy data rather } \\
\text { than chart review }\end{array}$ \\
\hline Charlson Index ${ }^{18}$ & $\begin{array}{l}\text { Derived in } 559 \text { US medical inpatients } \\
\text { Validated in } 685 \text { women receiving treat- } \\
\text { ment for breast cancer }\end{array}$ & $\begin{array}{l}\text { Various versions are available; } 17 \text { to } 22 \text { dis- } \\
\text { ease categories, including age } \\
\text { In different forms, can be administered by a } \\
\text { health professional on paper or electroni- } \\
\text { cally or self-completed as a questionnaire } \\
\text { Free }\end{array}$ & $\begin{array}{l}\text { To predict 1-year mortality } \\
\text { among patients admitted to } \\
\text { hospital } \\
\text { Later adapted to predict costs }{ }^{19}\end{array}$ \\
\hline $\begin{array}{l}\text { Adjusted Clinical } \\
\text { Groups (ACG) } \\
\text { System }^{25}\end{array}$ & $\begin{array}{l}\text { Derived and validated in US using large } \\
\text { HMO databases } \\
\text { Validation sample also included } 30,000 \\
\text { Medicaid recipients }\end{array}$ & $\begin{array}{l}\text { Age, sex, and diagnosis codes from medical } \\
\text { records or insurance claims coded using } \\
\text { the ICD or Read code systems } \\
\text { Data entered into ACG System software } \\
\text { available at cost under license }\end{array}$ & $\begin{array}{l}\text { Originally devised to predict } \\
\text { morbidity burden and use of } \\
\text { health care resources } \\
\text { System developed to provide a } \\
\text { number of tools with different } \\
\text { purposes }\end{array}$ \\
\hline $\begin{array}{l}\text { Cumulative Index } \\
\text { Illness Rating } \\
\text { Scale (CIRS) }\end{array}$ & $\begin{array}{l}\text { Hospitalized men in the United States } \\
\text { and subsequently older adults in } \\
\text { ambulatory settings }\end{array}$ & $\begin{array}{l}\text { A rating scale consisting of } 14 \text { body systems } \\
\text { categories that can be filled in by trained } \\
\text { assessors directly during clinical consulta- } \\
\text { tion or from medical records. } \\
\text { Free access }\end{array}$ & $\begin{array}{l}\text { To assess the medical burden of } \\
\text { chronic illness }\end{array}$ \\
\hline $\begin{array}{l}\text { (Duke Severity } \\
\text { Illness Check- } \\
\text { list (DuSOI) } \\
\text { index } 28-30\end{array}$ & $\begin{array}{l}\text { Developed in } 249 \text { adult patients attend- } \\
\text { ing a family practice in the United } \\
\text { States }\end{array}$ & $\begin{array}{l}\text { Severity of illness checklist for measuring a } \\
\text { person's illness severity } \\
\text { Can be filled in during clinical consultation } \\
\text { or from medical records } \\
\text { Available from author }\end{array}$ & $\begin{array}{l}\text { To quantify the burden of ill- } \\
\text { ness as measured by the } \\
\text { physician }\end{array}$ \\
\hline
\end{tabular}

ADGs = Adjusted Diagnosis Groups; CADGS = collapsed Aggregated Diagnosis Groups; HMO = health maintenance organization, ICD = International Classification of Diseases; MACs = major Adjusted Categories.

We extracted data about the characteristics of the study population, setting, outcome variables, study design, and main results into a Microsoft Access database.

We describe the measures identified below. Supporting tables provide details about the information needed to calculate each measure, along with details of which measures have shown evidence of validity by demonstrating associations with the specified patient, process, or outcome variables.

\section{RESULTS}

The searches yielded 11,191 references, of which 314 were potentially relevant and were reviewed in full text, leading to the inclusion of 194 articles that described 184 studies, some describing more than 1 multimorbidity measure (Supplemental Figure 1,
content/10/2/134/suppl/DC1). The majority of studies were of cross-sectional or longitudinal design.

Of the included studies, 76 were based on patients identified through their contact with generalist primary care, and 108 were conducted among people living in the community (not as patients). One-half of the studies ( $\mathrm{n}=97,53 \%)$ were conducted in the United States, with almost all of the remaining studies being conducted in Canada, Europe, or Australia.

Six measures were used in at least 5 studies. The characteristics and application of these measures are described in Table 1. The Appendix lists all the measures identified, including the lesser-used measures. Supplemental Tables 1, 2, and 3 (available at http:// annfammed.org/content/10/2/134/suppl/DC1) describe whether each measure has demonstrated validity through showing anticipated associations with patient demographic characteristics, health outcomes, or health care utilization. 
How Information Is Used

Single diseases added to give a total number of diseases/conditions per individual

Original CDS considered 17 disease states, weighted by an expert panel

Score based on history of dispensed drugs for 1 year, adjusted for age and sex

Subsequent versions used empirically derived weights and expanded number of diseases ${ }^{16,17}$

Each disease is given a weighting of 1 to 6 and weighted scores are summated; this score can also be combined with age

Variations have been developed to use ICD-9 data, namely, Romano et al (DartmouthManitoba score), ${ }^{20}$ Deyo et al, ${ }^{21} \mathrm{D}^{\prime}$ Hoore et al, ${ }^{22}$ Ghali et $a_{1}{ }^{23}$ Rius et al ${ }^{24}$

Collapsed into Initial Diagnosis Codes then to calculate ADGs (32); CADGs (12); MACs (26); ACGs (102). Each ACG includes individuals with a similar pattern of morbidity and similar expected resource use

Each body system has a severity rating of 0 to 4 , which are summated to create a total score (0-56), or presented as an index based on the number of categories scoring 2 or more.

Several variations exist

Each diagnosis is rated on 4 levels: symptom, complication, prognosis without treatment, prognosis with treatment

Various severity scores are calculated using the ratings (from 0 to 4 ) for each parameter of every diagnosis

\section{Comments}

No weighting of diseases regarding severity or prognosis

Limited number of disease states

Weighting of original CDS based on consensus rather than empirical data (addressed by subsequent versions)

Limited number of diseases

Prognoses vary between cancers yet have similar rating

Needs information about severity of some conditions

Prognosis for some conditions has improved since index developed

Need to purchase bespoke software

Based on records or claims data so dependent on reliability of those data

Requires training based on a manual. Broad body system groups

Prognoses vary among types of condition and may have improved since index was devised

Subjective judgment is required on the part of the assessor

Requires training

are taken as proxies for the existence of chronic disease (Table 1). The CDS has shown anticipated relationships with self-rated health status, functional status, hospitalization rates, and mortality. ${ }^{15,16,43,47-52}$ The original version $^{15}$ considered 17 disease states with weights predefined by an expert panel. Notable subsequent versions include Clark et al's revised $\mathrm{CDS}^{16}$ and RxRisk. ${ }^{17}$ Clark and colleagues considered an expanded number of diseases using weights for health utilization and costs derived empirically using health maintenance organization data. The RxRisk score, developed by Fishman et al, further expanded and revised the CDS, focusing on the estimation of future health care costs and increasing applicability to a wider range of pharmacy data sets and to children. Studies using the RxRisk model have shown anticipated associations with a wide range of variables (Supplemental Tables 1, 2, and 3).

\section{Charlson Index and Variations: 38 Studies}

Charlson et al developed this score for evaluating prognosis based on age and weightings for

\section{Disease Counts: 98 Studies}

Disease counts were defined as a simple unweighted enumeration of the number of diseases. Disease counts specify whether the person has 1 or more of a limited list of conditions, but the conditions included in this list varied in different studies from 9 to 35 different items. These items may have been individual conditions, diseases, health problems, or categories of conditions or diseases. Disease counts may be self-rated, clinician-rated, or extracted from records. Disease counts are the most commonly used measure of multimorbidity and have been used mainly in relation to patient demographic characteristics and health outcomes and to a lesser extent process measures.

\section{Chronic Disease Score (9 Studies)/RxRisk (8 Studies)}

The Chronic Disease Score (CDS) uses pharmacy dispensing data to identify classes of medication that specific comorbid conditions. ${ }^{18}$ The validity of the Charlson index has been studied more extensively than other measures, particularly in hospital and specialist settings. Although it was developed and validated in hospitalized patients, it has since been adapted and validated in primary care and community populations. ${ }^{19,50,51,53}$ There are several variations of the Charlson index, but studies comparing these variations suggest they produce similar results. ${ }^{21,51,54-56}$ The majority of studies using the Charlson index described the effect of multimorbidity on health outcomes, particularly mortality.

\section{Adjusted Clinical Groups System: 25 Studies}

The Adjusted Clinical Groups (ACG) System, a population/patient case-mix adjustment system based on medical records or insurance claims, measures health status by grouping diagnoses into clinically cogent groups. The ACG System was originally designed 
to predict future morbidity and use of health care resources. ${ }^{25}$ Most studies of the ACG System described predictive models for a range of cost or process outcomes associated with multimorbidity.

\section{Cumulative Index Illness Rating Scale: 10 Studies}

The Cumulative Index Illness Rating Scale (CIRS) index uses a scoring system that includes 14 body system domains and a severity scale for each domain. The CIRS can be applied directly in consultations or from medical records (Table 1). Studies of the CIRS have found associations with a range of patient demographic characteristics, measures of process and health care utilization, and health outcomes. One study compared CIRS scored through direct patient observation or chart review and also assessed interrater and intrarater reliability. All methods produced comparable results. ${ }^{57}$

\section{Duke Severity of Illness: 6 Studies}

Duke Severity of Illness (DUSOI) is a tool for measuring a person's illness severity that comprises 4 parameters of each diagnosis, namely, symptoms, complications, prognosis without treatment, and treatment potential. DUSOI can be completed at a consultation or from chart review. A few studies of the DUSOI demonstrated associations with age and sex, health care utilization, and quality of life. Parkerson et al found good interrater reliability for the DUSOI when rated by a physician or an auditor. ${ }^{28,29}$

\section{Other Measures: 21 Studies}

Eleven other types of multimorbidity measure were used in studies, often in comparison with other measures (Appendix). These studies all described associations also found by more commonly used multimorbidity measures.

\section{Comparison Studies: 15 Studies}

Several studies have directly compared how different measures of multimorbidity were associated with relevant variables in generalist primary care or community settings.* Most of these articles suggested that the performance of the different measures studied was similar. $17,29,44,47,50,51,58,61$ The Charlson index and the ACG System appeared to be the strongest predictors of mortality, ${ }^{47,50}$ whereas the ACG System and measures based on medication prescribed (Appendix) were strongest at predicting health care utilization. 17,50,51,53 Measures that include an assessment of functional status or subjective disease burden appear to be stronger predictors of a range of health outcomes than those that count diseases without adjustment for their sever-

* References 17,29,44,47,49-51,53,55,58-60. ity or impact. ${ }^{41,58-60}$ Some studies have shown that combining different types of measures improves the overall predictive performance of models. ${ }^{29,41,51,60}$ Two studies have suggested that simple measures perform almost as well as more complex measures, for example, using a count of prescribed medications to predict health care utilization or a simple count from a list of major chronic diseases to predict mortality. ${ }^{47,50}$

\section{DISCUSSION}

\section{Summary of Main Findings}

This review provides an index of previous literature for investigators seeking to use a multimorbidity measure in relation to a particular outcome. Researchers interested in the relationship between multimorbidity and health care utilization will find most evidence for the validity of the Charlson index, the ACG System, and disease counts. Evidence of validity in relation to patient or health service costs is strongest for the ACG System. For studies of the relationship between multimorbidity and mortality, the evidence is strongest for the Charlson index. The most commonly used measures of multimorbidity in relation to patient functioning or quality of life are disease counts and the Charlson index, but some studies have suggested that the CIRS is actually superior, ${ }^{58,62}$ as are measures that incorporate self-reported disease impact and severity. ${ }^{41}$ That other measures have been used less often in relation to these outcomes does not necessarily mean that they are less valid, but their performance has been less well established.

\section{Choice of Measure}

The choice of measure is likely to be based on the suitability of the measure for the data available as well as the outcome of interest. The Charlson index, ACG System, disease counts, and prescription counts can all be calculated from patient records, and these measures are particularly suitable for cross-sectional studies based on electronic records or administrative data. Both the CIRS and DUSOI, however, require judgment about individual patients (also requiring manuals and training to ensure reliability) and cannot be automated for use with large volumes of data.

Measures based on routine data may be easy to use, but ease of use needs to be balanced against the quality of the data. All measures are dependent on the range of conditions recorded, how accurately and recently these conditions were recorded, and whether there is information about the severity and impact of conditions. Measures using clinician ratings or patient self-report will be up-to-date and may be more accurate at predicting functional outcomes if they include 
assessment of severity or disability. These measures, however, are often based on a more restricted list of diseases than measures based on records.

There are limitations to measures that use complex scoring. Changes to disease coding systems may mean that weights need to be reestimated, and relevant drugs used in medication-based measures are constantly changing, so scoring algorithms need regular updating. Proprietary risk adjustment systems, such as the ACG System, tend to use scoring systems that are not transparent and often have considerable costs to end-users.

The most common approach to measuring multimorbidity is disease counts. Even so, it is hard to compare findings between studies, as different authors have included very different numbers of diseases, sometimes providing no details about which diseases are included or the criteria for inclusion. ${ }^{63}$ Most studies are based on counting so-called chronic diseases, but chronicity is rarely defined. The number of diseases is also related to the level of disease abstraction-for example, some measures count cancer as one condition, whereas others count each malignancy separately. ${ }^{63}$

It might be anticipated that such measures as the Charlson index, the ACG System, and the DUSOI, which weight different conditions, would be more effective at predicting outcomes than simple counts, which weight all conditions equally. Some studies, however, have concluded that simple measures, such as a simple count of chronic diseases or of prescribed medications, are almost as effective at predicting mortality and health care utilization as more sophisticated methods and may be much simpler (and also less expensive) to use despite the reservations outlined above. ${ }^{47,50}$

Part of the problem in choosing an appropriate measure is due to the abstract nature of the concept of multimorbidity and how it relates to other concepts, such as disease burden and patient complexity. ${ }^{1}$ It is important that measures are based on an underlying conceptualization of why and how multimorbidity is expected to have an impact on other variables. For example, the impact of multimorbidity on quality of life is likely to be most appropriately assessed using a self-report measure that takes account of functional ability, ${ }^{41}$ whereas the impact on health care utilization is likely to be best assessed using a measure that was derived using empirical weights to predict this outcome. ${ }^{64,65}$
Relatively few studies have directly compared the performance of different measures in a primary care context, and the findings do not show the clear superiority of one measure over another. Evidence about the reliability of these measures when used in a primary care or population setting is also limited. Evidence about the reliability of measures when used in hospitalized patients and specialist secondary care settings ${ }^{9}$ may not necessarily pertain to primary care settings, where patient characteristics, disease classifications, record systems, and staffing are very different.

\section{Strengths and Limitations}

This article builds on previous reviews of comorbidity measures in the context of specific index diseases ${ }^{9,66,67}$ by assessing the use of multimorbidity measures in generalist primary care and population settings. Multimorbidity is not well indexed in the literature, so it is unlikely that we have found all studies that would fit our inclusion criteria. We are aware that a number of risk adjustment models have been developed within the US health insurance system which have not been used frequently within academic research. ${ }^{68}$ Included studies used a variety of methods, and we have not set out to assess individual study quality. The methods used to derive each measure also differ considerably; therefore, comparing measures directly is fraught with both the inherent biases in the original studies plus the potential biases introduced by a systematic review, especially one of observational studies that have used different study designs. In some cases it was debatable whether the setting of a study should be considered as primary care ; we resolved such issues through discussion. We are confident that our review reflects the range and application of multimorbidity measures in the primary care and population context.

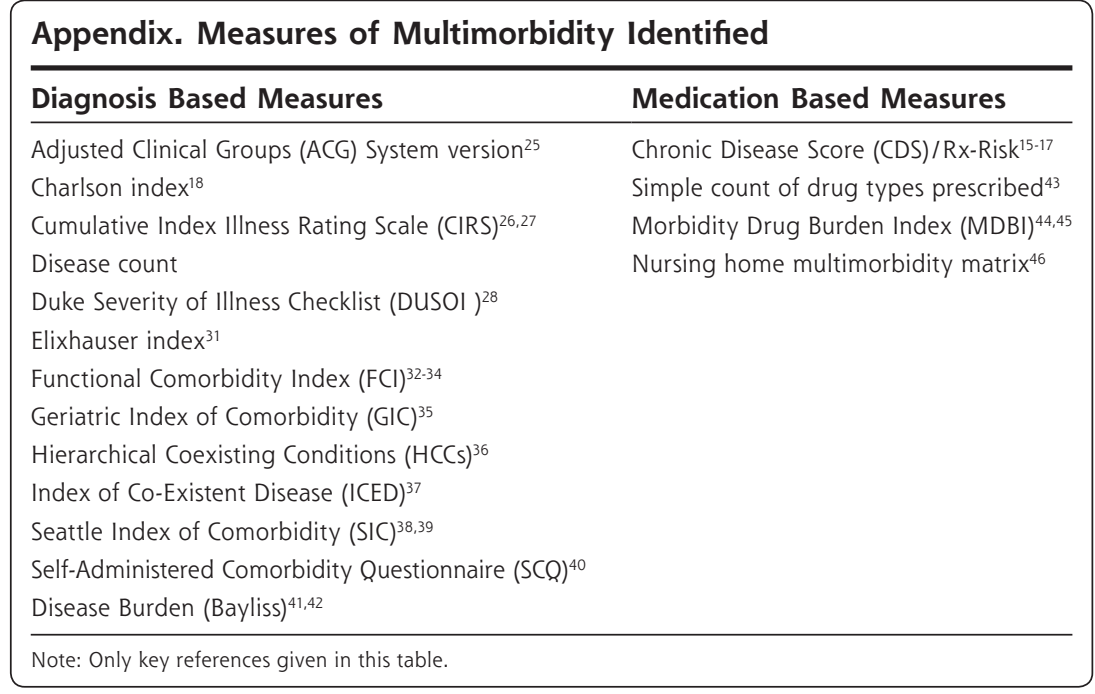




\section{Implications}

Different measures are needed to assess associations with different outcomes and the choice of measure will also depend on the type of data available. The measures that have been most widely used and for which there is greatest evidence of validity are the Charlson index, disease counts, and the ACG System. Other measures such as the CIRS and the DUSOI are more complex to administer, and their advantages over easier methods have not been well established. Measures based on counts of prescribed medication appear promising but need further research.

To read or post commentaries in response to this article, see it online at http://www.annfammed.org/content/10/2/134.

Submitted June 8, 2011; submitted, revised, November 10, 2011; accepted November 30, 2011.

Key words: comorbidity; multimorbidity; diagnosis-related groups; ambulatory care; primary health care; family practice

Funding support: This study was funded by the National Institute for Health Research, School for Primary Care Research.

Prior presentation: Preliminary data from this report have been presented as a poster at the annual meeting of the Society of Academic Primary Care (SAPC), April 2010, Norwich, England.

\section{References}

1. Valderas JM, Starfield B, Sibbald B, Salisbury C, Roland M. Defining comorbidity: implications for understanding health and health services. Ann Fam Med. 2009;7(4):357-363.

2. Fortin M, Lapointe L, Hudon C, Vanasse A. Multimorbidity is common to family practice: is it commonly researched? Can Fam Physician. 2005;51:244-245.

3. Salisbury C, Johnson L, Purdy S, Valderas JM, Montgomery AA. Epidemiology and impact of multimorbidity in primary care: a retrospective cohort study. Br J Gen Pract. 2011;61(582):e12-e21.

4. Fortin M, Bravo G, Hudon C, Vanasse A, Lapointe L. Prevalence of multimorbidity among adults seen in family practice. Ann Fam Med. 2005;3(3):223-228.

5. Wolff JL, Starfield B, Anderson G. Prevalence, expenditures, and complications of multiple chronic conditions in the elderly. Arch Intern Med. 2002;162(20):2269-2276.

6. Fortin M, Lapointe L, Hudon C, Vanasse A, Ntetu AL, Maltais D. Multimorbidity and quality of life in primary care: a systematic review. Health Qual Life Outcomes. 2004;2:51.

7. Fortin M, Dubois MF, Hudon C, Soubhi H, Almirall J. Multimorbidity and quality of life: a closer look. Health Qual Life Outcomes. 2007;5:52.

8. Keles H, Ekici A, Ekici M, Bulcun E, Altinkaya V. Effect of chronic diseases and associated psychological distress on health-related quality of life. Intern Med J. 2007;37(1):6-11.

9. de Groot V, Beckerman H, Lankhorst GJ, Bouter LM. How to measure comorbidity. a critical review of available methods. J Clin Epidemiol. 2003;56(3):221-229.

10. McDowell I. Measuring Health: A Guide to Rating Scales and Questionnaires. 3rd ed. Cambridge: Oxford University Press; 2006.
11. Streiner DL, Norman GR. Health Measurement Scales: A Practical Guide to Their Development and Use. 4th ed. Cambridge: Oxford University Press; 2008.

12. International Research Community on Multimorbidity. http://www. usherbrooke.ca/crmcspl/en/international-research-community-onmultimorbidityl. Accessed Nov 2, 2010.

13. John Hopkins ACG system. http://www.acg.jhsph.org/. Accessed Nov 2, 2010.

14. From the Centers for Disease Control. From the Centers for Disease Control. Comorbidity of chronic conditions and disability among older persons-United States, 1984. JAMA. 1990;263(2):209-210.

15. Von Korff M, Wagner EH, Saunders K. A chronic disease score from automated pharmacy data. J Clin Epidemiol. 1992;45(2):197-203.

16. Clark DO, Von Korff M, Saunders K, Baluch WM, Simon GE. A chronic disease score with empirically derived weights. Med Care. 1995;33(8):783-795.

17. Fishman PA, Goodman MJ, Hornbrook MC, Meenan RT, Bachman DJ, O'Keeffe Rosetti MC. Risk adjustment using automated ambulatory pharmacy data: the RxRisk model. Med Care. 2003;41(1):84-99.

18. Charlson ME, Pompei P, Ales KL, Mackenzie CR. A new method of classifying prognostic comorbidity in longitudinal studies: development and validation. J Chronic Dis. 1987;40(5):373-383.

19. Charlson ME, Charlson RE, Peterson JC, Marinopoulos SS, Briggs WM, Hollenberg JP. The Charlson comorbidity index is adapted to predict costs of chronic disease in primary care patients. J Clin Epidemiol. 2008;61(12):1234-1240.

20. Romano PS, Roos LL, Jollis JG. Adapting a clinical comorbidity index for use with ICD-9-CM administrative data: differing perspectives. J Clin Epidemiol. 1993;46(10):1075-1079, discussion 1081-1090.

21. Deyo RA, Cherkin DC, Ciol MA. Adapting a clinical comorbidity index for use with ICD-9-CM administrative databases. J Clin Epidemiol. 1992;45(6):613-619.

22. D'Hoore W, Sicotte C, Tilquin C. Risk adjustment in outcome assessment: the Charlson comorbidity index. Methods Inf Med. 1993;32(5): 382-387.

23. Ghali WA, Hall RE, Rosen AK, Ash AS, Moskowitz MA. Searching for an improved clinical comorbidity index for use with ICD-9-CM administrative data. J Clin Epidemiol. 1996;49(3):273-278.

24. Rius C, Rodriquez-Sanz M, Fernandez E.Comorbidity index was successfully validated among men but not in women. J Clin Epidemiol. 2008;61(8):798-802.

25. Starfield B, Weiner J, Mumford L, Steinwachs D. Ambulatory care groups: a categorization of diagnoses for research and management. Health Serv Res. 1991;26(1):53-74.

26. Linn BS, Linn MW, Gurel L. Cumulative illness rating scale. J Am Geriatr Soc. 1968;16(5):622-626.

27. Miller MD, Paradis $C F$, Houck PR, et al. Rating chronic medical illness burden in geropsychiatric practice and research: application of the Cumulative Illness Rating Scale. Psychiatry Res. 1992;41(3):237-248.

28. Parkerson GR Jr, Broadhead WE, Tse CK. The Duke Severity of IIIness Checklist (DUSOI) for measurement of severity and comorbidity. J Clin Epidemiol. 1993;46(4):379-393.

29. Parkerson GR Jr, Harrell FE Jr, Hammond WE, Wang XQ. Characteristics of adult primary care patients as predictors of future health services charges. Med Care. 2001;39(11):1170-1181.

30. Parkerson GR Jr, Michener JL, Wu LR, et al. Associations among family support, family stress, and personal functional health status. J Clin Epidemiol. 1989;42(3):217-229.

31. Elixhauser A, Steiner C, Harris DR, Coffey RM. Comorbidity measures for use with administrative data. Med Care. 1998;36(1):8-27.

32. Selim AJ, Fincke G, Ren XS, et al. Comorbidity assessments based on patient report: results from the Veterans Health Study. J Ambul Care Manage. 2004;27(3):281-295. 
33. Yeo J, Karimova G, Bansal S. Co-morbidity in older patients with COPD -its impact on health service utilisation and quality of life, a community study. Age Ageing. 2006;35(1):33-37.

34. Groll DL, To T, Bombardier C, Wright JG. The development of a comorbidity index with physical function as the outcome. J Clin Epidemiol. 2005;58(6):595-602.

35. Rozzini R, Frisoni GB, Ferrucci L, et al. Geriatric Index of Comorbidity: validation and comparison with other measures of comorbidity. Age Ageing. 2002;31(4):277-285.

36. Pope GC, Ellis RP, Ash AS, et al. Diagnostic Cost Group Hierarchical Condition Category Models for Medicare Risk Adjustment. Final Report to the Health Care Financing Adminstration Under Contract Number 500-95-048. Waltham, MA; Health Economics Research, Inc, December, 2000.

37. Greenfield S, Sullivan L, Dukes KA, Silliman R, D'Agostino R, Kaplan $\mathrm{SH}$. Development and testing of a new measure of case mix for use in office practice. Med Care. 1995;33(4)(Suppl):AS47-AS55.

38. Fan VS, Au D, Heagerty P, Deyo RA, McDonell MB, Finn SD. Validation of case-mix measures derived from self-reports of diagnoses and health. J Clin Epidemiol. 2002;55(4):371-380

39. DeSalvo KB, Fan VS, McDonell MB, Fihn SD. Predicting mortality and healthcare utilization with a single question. Health Serv Res. 2005;40(4):1234-1246.

40. Sangha O, Stucki G, Liang MH, Fossel AH, Katz JN. The Self-Administered Comorbidity Questionnaire: a new method to assess comorbidity for clinical and health services research. Arthritis Rheum. 2003;49(2):156-163.

41. Bayliss EA, Ellis JL, Steiner JF. Seniors' self-reported multimorbidity captured biopsychosocial factors not incorporated into two other data-based morbidity measures. J Clin Epidemiol. 2009;62(5):550557, e1.

42. Bayliss EA, Ellis JL, Steiner JF, Main DS. Initial validation of an instrument to identify barriers to self-management for persons with co-morbidities. Chronic Illn. 2005;1(4):315-320.

43. Schubert CC, Boustani M, Callahan CM, et al. Comorbidity profile of dementia patients in primary care: are they sicker? J Am Geriatr Soc. 2006;54(1):104-109.

44. Vitry A, Wong SA, Roughead EE, Ramsay E, Barratt J. Validity of medication-based co-morbidity indices in the Australian elderly population. Aust N ZJ Public Health. 2009;33(2):126-130.

45. George J, Vuong T, Bailey MJ, Kong DC, Marriott JL, Stewart K. Development and validation of the medication-based disease burden index. Ann Pharmacother. 2006;40(4):645-650.

46. Akner G. Analysis of multimorbidity in individual elderly nursing home residents. Development of a multimorbidity matrix. Arch Gerontol Geriatr. 2009;49(3):413-419.

47. Di Bari M, Virgillo A, Matteuzzi D, et al. Predictive validity of measures of comorbidity in older community dwellers: the Insufficienza Cardiaca negli Anziani Residenti a Dicomano Study. J Am Geriatr Soc 2006;54(2):210-216.

48. Harpole LHW, Williams JW Jr, Olsen MK, et al. Improving depression outcomes in older adults with comorbid medical illness. Gen Hosp Psychiatry. 2005;27(1):4-12.

49. Mayo NE, Nadeau L, Levesque L, Miller S, Poissant L, Tamblyn R. Does the addition of functional status indicators to case-mix adjustment indices improve prediction of hospitalization, institutionalization, and death in the elderly? Med Care. 2005;43(12):1194-1202.

50. Perkins AJK, Kroenke K, Unützer J, et al. Common comorbidity scales were similar in their ability to predict health care costs and mortality. J Clin Epidemiol. 2004;57(10):1040-1048.
51. Schneeweiss S, Wang PS, Avorn J, Maclure M, Levin R, Glynn RJ Consistency of performance ranking of comorbidity adjustment scores in Canadian and U.S. utilization data. J Gen Intern Med. 2004;19(5 Pt 1):444-450.

52. Koike AK, Unützer J, Wells KB. Improving the care for depression in patients with comorbid medical illness. Am J Psychiatry. 2002;159(10): 1738-1745.

53. Dominick KL, Dudley TK, Coffman CJ, Bosworth HB. Comparison of three comorbidity measures for predicting health service use in patients with osteoarthritis. Arthritis Rheum. 2005;53(5):666-672.

54. Dorr DA, Jones SS, Burns L, et al. Use of health-related, quality-oflife metrics to predict mortality and hospitalizations in communitydwelling seniors. J Am Geriatr Soc. 2006;54(4):667-673.

55. Tang J, Wan JY, Bailey JE. Performance of comorbidity measures to predict stroke and death in a community-dwelling, hypertensive Medicaid population. Stroke. 2008;39(7):1938-1944.

56. Walter LC, Lindquist $K$, Nugent $S$, et al. Impact of age and comorbidity on colorectal cancer screening among older veterans. Ann Intern Med. 2009;150(7):465-473.

57. Hudon C, Fortin M, Vanasse A. Cumulative Illness Rating Scale was a reliable and valid index in a family practice context. J Clin Epidemiol. 2005;58(6):603-608

58. Fortin M, Hudon C, Dubois MF, Almirall J, Lapointe L, Soubhi H. Comparative assessment of three different indices of multimorbidity for studies on health-related quality of life. Health Qual Life Outcomes. 2005;3:74.

59. Bayliss EA, Ellis JL, Steiner JF. Subjective assessments of comorbidity correlate with quality of life health outcomes: initial validation of a comorbidity assessment instrument. Health Qual Life Outcomes. 2005;3:51-58

60. Gabriel SE, Crowson CS, O'Fallon WM. A comparison of two comorbidity instruments in arthritis. J Clin Epidemiol. 1999;52(12):1137-1142.

61. Yan Y, Birman-Deych E, Radford MJ, Nilasena DS, Gage BF. Comorbidity indices to predict mortality from Medicare data: results from the national registry of atrial fibrillation. Med Care. 2005;43(11):1073-1077.

62. Fortin M, Bravo G, Hudon C, Lapointe L, Dubois MF, Almirall J. Psychological distress and multimorbidity in primary care. Ann Fam Med. 2006;4(5):417-422.

63. Diederichs C, Berger K, Bartels DB. The measurement of multiple chronic diseases - a systematic review on existing multimorbidity indices. J Gerontol A Biol Sci Med Sci. 2011;66(3):301-311.

64. Byles J, D'Ester C, Parkinson L, O'Connell R, Treloar C. Single index of multimorbidity did not predict multiple outcomes. J Clin Epidemiol 2005; 58(10):-997

65. Tooth L, Hockey R, Byles J, Dobson A. Weighted multimorbidity indexes predicted mortality, health service use, and health-related quality of life in older women. J Clin Epidemiol. 2008;61(2):151-159.

66. Harboun M, Ankri J. Comorbidity indexes: review of the literature and application to studies of elderly population. Rev Epidemiol Sante Publique. 2001;49(3):287-298.

67. Extermann M. Measuring comorbidity in older cancer patients. Eur J Cancer. 2000;36(4):453-471.

68. Institute for Health Policy. Risk adjustment methods and their relevance to " pay or play". Supplement E to the report: Challenges and Alternatives for Employer Pay or Play Program Design: An Implementation and Alternative Scenario Analysis of California's " Health Insurance Act of 2003" (SB 2). http://www.chcf.org/ /media/MEDIA\%20 LIBRARY\%20Files/PDF/M/PDF\%20MRMIBSB2SupERiskAdj.PDF. Accessed Nov 9, 2011. 